\title{
Avaliação formativa e autorregulação: um estudo sobre os cadernos do PNAIC
}

\author{
Formative assessment and self-regulation: \\ a study on the PNAIC notebooks
}

Jussara Cristina Barboza TORTELLA ${ }^{1}$

Francisco Caloia ALFREDO²

Jady Ariele Cavalcanti RUAS 3

\begin{abstract}
Resumo
O objetivo geral deste artigo é o de verificar se os aspectos sobre a avaliação da aprendizagem mencionados nos Cadernos de Formaçáo do PNAIC estão consonantes com os fundamentos da avaliaçáo formativa na perspectiva cognitiva e da autorregulaçáo. Configura-se como estudo de análise documental. Os conteúdos sobre avaliação ora estão de acordo com a perspectiva cognitivista, ora aproximam-se mais de um controle. Há prioridadenas ações do professorenquanto a ação do aluno no processo de avaliaçáo é pouco destacada. Buscou-se compreender os procedimentos e instrumentos avaliativos da aprendizagem utilizados no PNAIC para consolidação da escola como um espaço fundamental de aprendizagens.
\end{abstract}

Palavras-chave: Avaliação da aprendizagem. Autorregulação. PNAIC.
Abstract

The overall objective of this paper is to see if the aspects of learning assessment mentioned in the PNAIC Training Manual are consonant with the foundations of formative assessment in the cognitive and self-regulation perspective. It is a study of documentary analysis. The content on evaluation is sometimes in agreement with the cognitive perspective, sometimes more as control. There is priority in the teacher's actions whereas the student's action is little highlighted in the evaluation process. This study sought to understand the procedures and instruments for learning assessment used in the PNAIC to consolidate the school as a fundamental area of learning.

Keywords: Evaluation of learning. Self-regulation. PNAIC.

1 Doutora em Educação pela Universidade Estadual de Campinas (Unicamp), Docente Permanente do Programa de Pós-Graduação em Educação da Pontifícia Universidade Católica de Campinas (PUCCampinas). Lattes: http://lattes.cnpq.br/7126514256674237, ORCID: https://orcid.org/0000-00029076-8739. E-mail: jussaratortella@gmail.com

2 Doutorado em Ciências da Educação pela Universidade do Minho (UMINHO), Professor no Instituto Superior Politécnico Independente do Lubango. Lattes: http://lattes.cnpq.br/2901864178910813, ORCID: https://orcid.org/0000-0002-1570-3679. E-mail: franciscocaloia10@gmail.com

3 Mestra em Educação pela Pontifícia Universidade Católica de Campinas (PUC-Campinas), Professora atuante na educação básica. Lattes: http://lattes.cnpq.br/3483575822041123, ORCID: https://orcid. org/0000-0002-3076-6416. E-mail: jadycavalcantii@gmail.com 


\section{Introdução}

Em tempos atuais há, notadamente, interesse dos órgãos oficiais na implementação de programas e projetos educacionais, sendo que a tônica, de forma geral, é a melhora do desempenho escolar e dos índices das avaliaçóes externas. Diante da complexidade do sistema educacional e dos resultados dessas avaliações, o olhar da comunidade escolar volta-se para a aprendizagem dos alunos. Em 2012 foi implementado o Pacto Nacional pela Alfabetização na Idade Certa (PNAIC), iniciativa do Governo Federal com o objetivo de alfabetizar todas as crianças das escolas municipais e estaduais até o final do Ciclo de Alfabetização, considerando as áreas de Língua Portuguesa e Matemática.

Os documentos oficiais indicam que, além das avaliaçóes externas, há que se aprimorar as avaliaçóes efetuadas no interior das escolas. A avaliação formativa, uma das propostas de avaliação apresentada no referido documento, trata de processos constantes de avaliação que procuram identificar os saberes já apropriados pelos alunos e as dificuldades ainda presentes para a efetivação e apreensão das aprendizagens. Com a identificação das dificuldades, o professor é capaz de replanejar suas açóes pedagógicas a fim de suprir as necessidades específicas de cada aluno, como também oferecer feedbacks para que os alunos busquem avaliar seu processo de aprendizagem e com a ajuda do professor possam buscar novas estratégias para se apropriarem dos conteúdos. A identificação das necessidades e dos acertos nas aprendizagens por meio da avaliação formativa possibilita que tanto o aluno como o professor desenvolvam processos de autorregulaçáo e autoavaliação no ensino e aprendizagem.

A autorregulação é um constructo definido como um processo ativo no qual os sujeitos estabelecem os objetivos que orientam suas aprendizagens, no sentido de monitorizar, regular e controlar cogniçóes, comportamentos e motivações a fim de alcançar os objetivos estabelecidos. Esse processo, cujos mecanismos atuam desde o nascimento do sujeito, se dá a partir de um movimento cíclico e dinâmico na busca da aquisição de conhecimentos, envolvendo não apenas os aspectos cognitivos, mas os motivacionais e afetivos (ZIMMERMAN, 2008; ZIMMERMAN; SCHUNK, 2011; HADJI, 2011; ROSÁRIO, 2004).

O objetivo geral deste artigo é verificar se os aspectos sobre a avaliação da aprendizagem mencionados nos Cadernos de Formação do PNAIC estão consonantes com os fundamentos da avaliação formativa na perspectiva cognitiva e da autorregulação. Como objetivo específico estabeleceuse: apresentar os fundamentos teóricos e instrumentos de avaliação da aprendizagem propostos nos Cadernos de Formação do PNAIC. Trata-se, portanto, de um estudo documental. 


\section{Pacto Nacional pela Alfabetização na Idade Certa}

Com a Emenda Constitucional no 59/2009, o Plano Nacional de Educação (PNE) passou de uma disposição transitória da Lei de Diretrizes e Bases da Educação Nacional no 9.394/1996 para uma exigência constitucional com periodicidade decenal, desde então se faz necessário que os legisladores dos âmbitos estaduais e municipais estabeleçam, em conjunto, metas e estratégias para alcançar os objetivos educacionais propostos. Em 2014 o PNE tornou-se oficialmente a Lei $n^{\circ} 13.005$, a qual apresenta vinte metas com respectivas estratégias para melhoria da qualidade da educação.

O Pacto Nacional pela Alfabetização na Idade Certa (PNAIC) é um programa formulado pelo Governo Federal brasileiro, sendo um dos esforços para assegurar a plena alfabetização dos alunos no período denominado "Ciclo Um" do Ensino Fundamental, ou seja, até os oito anos de idade. O PNAIC oriundo da "Meta 5" do PNE que estabelece em sua redação: "alfabetizar todas as crianças, no máximo, até o final do $3^{\circ}$ (terceiro) ano do ensino fundamental" (BRASIL, LEI No13.005 DE 2014), e este torna-se o principal objetivo do PNAIC.

A implementação do PNAIC é um compromisso assumido pelos governos Federal, dos Estados e dos Municípios, bem como a formação de professores e a distribuição do material didático. Ressalta-se que a decisão de adesão ao PNAIC é uma escolha individual dos professores alfabetizadores. Um novo programa, com objetivos próximos ao PNAIC, foi recentemente implementado. De acordo com o portal do MEC (2019), "o Programa Mais Alfabetização, criado pela Portaria no 142, de 22 de fevereiro de 2018, é uma estratégia do Ministério da Educaçáo para fortalecer e apoiar as unidades escolares no processo de alfabetização dos estudantes regularmente matriculados no $1^{\circ}$ ano e no $2^{\circ}$ ano do ensino fundamental ${ }^{4 \prime}$.

Estudos sobre o PNAIC, realizados recentemente, analisam diversas facetas, dentre elas, os princípios gerais de formação continuada (PARISOTTO; OLIVEIRA, 2016); os impactos do programa na formação matemática de Professores Alfabetizadores e sua relação com a cultura da performatividade (FERREIRA; FONSECA, 2017); a configuração da formação desse programa nas redes de ensino de Santa Catarina a partir dos relatórios dos Orientadores de Estudo (AGUIAR; BRICHI; ZAPATA, 2017); as relaçóes entre o Pacto pela Alfabetização na Idade Certa (PAIC), experiências educacionais realizadas na

4 Disponível em: <http://portal.mec.gov.br/programa-mais-educacao/30000-uncategorised/62871programa-mais-alfabetizacao >. Acesso em: 24 jun. 2019. 
educação básica do Ceará que serviram de base ao PNAIC (ALFLEN; VIEIRA, 2018); e as opçóes teórico-metodológicas empregadas pelo Pacto Nacional pela Alfabetização na Idade Certa (PNAIC) relacionadas à leitura de textos literários de ficção (ZANCHETTA JUNIOR, 2017). De forma geral, todos os estudos apontam para o impacto das orientaçóes propostas pelo programa para a formação dos professores e prática docente, as fragilidades e avanços para o processo de alfabetização. De forma específica, nenhum deles abordou a questão da avaliação.

De acordo com a proposta do PNAIC, quatro eixos de atuaçáo necessitam ser atendidos: "1). Formação continuada presencial para os professores alfabetizadores e seus orientadores de estudo; 2). Materiais didáticos, obras literárias, obras de apoio pedagógico, jogos e tecnologias educacionais; 3). Avaliações sistemáticas; e 4). Gestão, mobilização e controle social” (BRASIL, 2012). O presente artigo concentra-se no segundo eixo, especificamente as obras de apoio pedagógico.

\section{Avaliação Formativa e Autorregulação}

A avaliação, sendo um componente pedagógico presente em todo processo de ensino e de aprendizagem, não representa um fim em si, embora seja este muitas vezes o sentido que lhe é atribuído (ABRECHT, 1986). Entre as modalidades da avaliação, a avaliaçáo formativa é a mais congruente com o sucesso de todos os alunos e que permite maior autonomia aos professores. Permite ajustes ou aperfeiçoamentos necessários de programas, currículos e métodos de ensino durante a aplicação, o que difere da avaliação somativa, focada na realização do balanço de determinado ciclo (ABRECHT, 1986; SCALLON, 1988; ALLAL, 1986; CARDINET, 1988; ALVES, 2004; ESTEBAN, 1999; FERNANDES, 2005; HADJI, 2001, 2011; PERRENOUD, 1999).

Das contribuições no campo da avaliação formativa, sinalizamos a contribuição de Linda Allal (1986) para quem a avaliação formativa pode se conceber numa perspectiva cognitivista ou (neo) behaviorista. Sendo que, de acordo com a mesma autora, sobre esta última assenta a concepção de avaliação formativa proposta por Bloom e seus colaboradores, segundo a qual a avaliação formativa é "um componente essencial na realização da pedagogia da mestria ou de qualquer outra tentativa de individualização do ensino" (ALLAL, 1986, p. 176).

Portanto, a avaliação formativa sob orientação (neo)behaviorista recai sobre a adaptação das atividades para o ensino, o que quer dizer que as atividades são realizadas em função do comportamento manifestado pelos alunos e dos objetivos pedagógicos definidos. Há uma referenciação criterial das informações 
obtidas sobre os alunos, apesar da qual assume-se, geralmente, um tempo de reforço para os alunos, náo necessariamente a uma frequência, e as dificuldades manifestadas por estes podem ser ultrapassadas mediante a realizaçáo de atividades de recuperaçáo (ALLAL, 1986).

Outra concepção da avaliação formativa aplica-se na perspectiva cognitivista que, segundo Allal (1986), valoriza o recolhimento de informaçóes relativas aos resultados da aprendizagem do aluno, entretanto as informaçóes sobre os processos de aprendizagem ganham maior relevância, sendo com isso fundamental compreender como os alunos se mobilizam mentalmente em relação às atividades que lhes são propostas. Nesse sentido, a valorização dos processos utilizados por cada aluno para chegar a determinado resultado torna-se muito mais importante do que o resultado alcançado.

Ademais, a adaptação pedagógica permite que o aluno seja impulsionado por meios da interação com o professor e colegas, com a realização de trabalhos individuais ou coletivos, a descobrir e construir estratégias de aprendizagem (ALLAL, 1986; CARDINET, 1988). Assim, entre várias, define-se a avaliação formativa como "um processo de avaliação contínua tendo por objeto assegurar a progressão de cada indivíduo no processo de aprendizagem, com a intenção de modificar a situaçáo de aprendizagem ou o ritmo desta progressão para permitir melhorias ou correçôes apropriadas" (SCALLON, 1988, p. 155).

Hadji (2011) destaca a ideia central de avaliaçáo formativa como toda avaliação que permite ajudar o aluno a aprender e o professor a ensinar, sua função predominante é regular, isto é, "intervir em tempo real e ao longo do processo, nas aprendizagens dos alunos" (HADJI, 2011, p. 29). O grande desafio do professor é fazer a regulaçáo adequada que mais se aproxima e afeta as aprendizagens que são construídas nos processos mentais do aluno. Não se trata apenas de avaliar as atividades realizadas, mas conseguir diagnosticar dificuldades e colher informaçóes que subsidiem a organização e continuação da sequência de aprendizagem, de modo que venha a efetivar saberes.

Para Hadji (2011), não existe avaliação formativa sem a autorregulação, considerada como um processo complexo, no qual o aluno gera suas regulaçóes efetivamente de duas maneiras: regulações cognitivas e regulaçóes metacognitivas. A regulação, e consequente ensino ou aprendizagens bem sucedidos, ocorrem quando alguns fatores são preservados: estabelecer um objetivo e planejar açóes para o atingir; controlar ações e tempo considerando os objetivos estabelecidos; envolverse ou acompanhar o envolvimento na tarefa; dar constantes feedbacks durante a execução da ação; e avaliar se as ações foram efetivas para se atingir o objetivo ou se há necessidade da busca de ajuda (ALLAL, 1986; LOURENÇO; PAIVA, 2016).

Ter o controle da própria aprendizagem náo é algo simples. No contexto escolar, requer constantes construçôes e, se dá, principalmente, a partir de 
intervençóes intencionais dos docentes. Quando o aluno é capaz de mobilizar suas regulaçóes metacognitivas, tornando-se autorregulador da própria aprendizagem, ele se torna cada vez menos dependente de ajudas externas, pois é capaz de antecipar, controlar e ajustar os processos que intervém na regulação. A metacognição refere-se à consciência do processo de aprendizagem, de como automonitorar e autorregular o ato de aprender, "a apropriaçáo e comando dos recursos internos se relacionando com os objetos externos" (DANTAS; RODRIGUES, 2013, p. 227).

A autorregulação se dá por meio de processos de antecipação, controle e ajuste. A antecipação "é uma operação pela qual um sujeito organiza as suas representaçóes de modo a poder orientar a sua açáo" (HADJI, 2011, p.47), ou seja, é a forma como o aluno elabora uma base de orientação da sua ação, permitindo que ela guie seus processos de ação e produção. Para realizar o controle, o monitoramento da ação, o aluno necessita comparar aquilo que planejou com a ação em desenvolvimento, fazendo constantemente ajustes necessários.

É no campo das operaçóes metacognitivas de controle que se situa a avaliação, pois é nesse processo em que se verifica a situação ideal ou referente (almejada) e a situação real ou referida que é percebida através de sinais representativos do processo de aprendizagem do aluno. $\mathrm{O}$ acompanhamento do ajuste é o objetivo principal do professor que pratica a avaliaçáo formativa, como o próprio termo sugere "é a operação pela qual o sujeito aprendente modifica ou reorienta os seus processos de produção" (HADJI, 2011, p.48).

A autoavaliação funciona como um mecanismo de verificação que torna a avaliação um processo contínuo, é uma atividade exercida única e exclusivamente pelo agente (professor ou aluno), a fim de se monitorar o andamento do processo em busca do êxito em seu objetivo; a autorregulaçấo acompanha todo o processo de execução e gerenciamento da tarefa para atingir tais objetivos. Permite que o aluno trabalhe no nível da metacognição. "A autoavaliação pode ser um dos elementos da autorregulação, que visa permitir ao aluno uma apreciação (constatação e julgamento) das modalidades ou dos resultados da atividade em questáo" (HADJI, 2011, p.50). Isso também pode se aplicar à tarefa do professor.

Frente ao exposto, compreende-se a avaliaçáo formativa como um caminho para promoção de aprendizagens significativas e de um ensino democrático, a qual permite que as crianças tomem decisóes sobre suas aprendizagens e respeita o desenvolvimento de cada uma, permitindo que todas alcancem os objetivos de aprendizagem. É com base nesse pressuposto teórico ora apresentado e na importância da avaliação formativa e da autorregulação no processo de aprendizagem que se analisou o material do PNAIC. 


\section{Procedimentos Metodológicos}

A presente pesquisa, de caráter bibliográfico, se caracteriza como um estudo de análise documental. Os documentos, na área educacional, podem ser considerados como uma importante fonte de dados (MARCONI; LAKATOS, 2007). Utilizou-se arquivos públicos, disponíveis no site do Ministério da Educação (http://pacto.mec.gov.br/index.php).

A investigação contou com o recurso da internet para a coleta das informaçóes que eram objetos da pesquisa - Cadernos de Formação do PNAIC. Foram analisados no total os textos dos 48 cadernos disponíveis no site oficial do PNAIC em arquivo PDF. Explorou-se o material em unidades de registro, sendo que para cada caderno utilizou-se a ferramenta localizar com a palavra-chave "avaliaç". Organizou-se um arquivo para cada caderno com título, número de incidências da palavra "avaliaç" e a inserção dos parágrafos que continham a referida palavra. Posteriormente, realizou-se a leitura do material garantindo os passos propostos por Bardin (2011), a pré-análise considerando as regras da exaustividade, da representatividade, da homogeneidade, e de pertinência.

Estabeleceu-se a unidade de contexto, organizando os trechos selecionados naquilo que os aproximava ou os distanciava, ou seja, realizou-se a análise do parágrafo para evidenciar a unidade de contexto em que estava inserida e para cada parágrafo utilizou-se uma nova palavra-chave que caracterizava o conteúdo principal. Segundo Bardin (2011, p. 133), a unidade de contexto "corresponde ao segmento da mensagem que possibilita a significaçáo precisa da unidade de registro". Se após a leitura do parágrafo não fora possível evidenciar o conteúdo, voltava-se ao documento original e realizava-se uma nova leitura de parágrafos anteriores e posteriores; este mesmo procedimento foi realizado com todos os cadernos.

Dos 48 cadernos, apenas três não tiveram incidência da palavra-chave. Em um segundo momento, realizou-se uma nova leitura do material e a partir dela organizaram-se novos arquivos com onze eixos de análise, a saber: Avaliação formativa; Avaliaçóes em larga escala; Sugestôes de atividades para professores; Depoimento de professores; Açôes docentes; Procedimentos e instrumentos de avaliação; Formação de professores e gestores; Ações discentes; Sugestôes de vídeos e leituras; Notas de rodapé, Referências, Fichas catalográficas e Sumário; Discussóes diversas; e Incidências em títulos. Os cinco último seixos descritos foram descartados, pois não trouxeram dados relevantes para a pesquisa.

5 Utilizou-se apenas a abreviação "avaliaç", considerando a sufixação (avaliaçẫo, avaliaçôes). 
Por fim, organizou-se as categorias de análise que, segundo Bardin (2011, p. 117), emergem por meio de uma "operação de classificação de elementos constitutivos de um conjunto, por diferenciação e, seguidamente, por reagrupamento segundo o gênero (analogia), com os critérios previamente definidos". Os dados foram organizados conforme proposto pelo autor: em cada uma das categorias apresentam-se as incidências contidas nos onze eixos de análise, um texto introdutório que as fundamentam, bem como trechos que as exemplificam. Organizaram-se três grandes categorias que englobam os onze eixos conforme sua aproximação temática e de conteúdo, para posteriormente analisá-los criticamente.

\section{Discussão dos resultados}

A partir da organização dos eixos elaboraram-se três categorias de análise: Processos de Avaliação, Formação Docente e Formação Discente. A primeira categoria engloba os eixos cujos conteúdos referem-se à avaliaçáo em diversas dimensóes. A segunda refere-se aos conteúdos que estáo relacionados às açóes, atividades e processos da formação e profissão docente. E a terceira categoria está relacionada com os conteúdos que mencionam a atividade discente no processo de formação do PNAIC. O quadro 1 sistematiza a organização das categorias e eixos e suas incidências nos documentos analisados:

Quadro 1. Categorias e Incidências

\begin{tabular}{|c|c|c|c|c|}
\hline Categorias & Eixos englobados nas categorias & $\begin{array}{l}\text { Número de } \\
\text { cadernos }\end{array}$ & $\begin{array}{l}\text { Número de } \\
\text { incidências }\end{array}$ & $\begin{array}{c}\text { Total de } \\
\text { incidências }\end{array}$ \\
\hline \multirow{3}{*}{$\begin{array}{l}\text { Processos de } \\
\text { Avaliação }\end{array}$} & Avaliação formativa & 25 & 181 & \multirow{3}{*}{329} \\
\hline & Avaliações em larga escala & 13 & 107 & \\
\hline & $\begin{array}{l}\text { Procedimentos e instrumentos de } \\
\text { avaliação }\end{array}$ & 15 & 41 & \\
\hline \multirow{4}{*}{$\begin{array}{l}\text { Formação } \\
\text { docente }\end{array}$} & $\begin{array}{l}\text { Sugestões de atividades para } \\
\text { professores }\end{array}$ & 18 & 56 & \multirow{4}{*}{183} \\
\hline & Depoimento de professores & 17 & 46 & \\
\hline & Ações docentes & 21 & 44 & \\
\hline & Formação de professores e gestores & 06 & 37 & \\
\hline $\begin{array}{l}\text { Formação } \\
\text { discente }\end{array}$ & Ações discentes & 09 & 18 & 18 \\
\hline \multicolumn{5}{|c|}{ Total geral de incidências: 530} \\
\hline
\end{tabular}

Fonte: dados da pesquisa. 
A quantificação das incidências sobre o conteúdo da avaliação proposto nos cadernos do PNAIC revela que há uma priorização da avaliaçáo formativa $(\mathrm{n}=181)$, da avaliação em larga escala $(\mathrm{n}=107)$ e da sugestão de atividades para os professores $(\mathrm{n}=56)$. Quando comparamos esses eixos com as açóes discentes $(\mathrm{n}=18)$, nota-se uma grande diferença.

\section{Categoria 1. Processos de avaliação}

- Avaliação formativa:

Os cadernos que trouxeram a perspectiva de avaliação formativa trataram a proposta entrelaçada aos termos de avaliação diagnóstica, processual e contínua. No total apareceram 181 incidências em 25 cadernos. Em muitas passagens, os cadernos trazem a proposta de avaliação do PNAIC, evidenciando o modelo de avaliação formativa. O programa entende a avaliação formativa como um dos elementos que contribuem para alcançar suas metas, oportunizando aprendizagens significativas e efetivas, em busca do sucesso escolar e da plena alfabetização do aluno ao terceiro ano do primeiro ciclo. A avaliação formativa é considerada uma ferramenta, capaz de promover a inclusão, garantindo assim que os direitos de aprendizagens sejam efetivados até o final do ciclo (cf. BRASIL, Cad. 1, 2015).

O PNAIC propóe que a avaliaçáo formativa seja realizada em todos os âmbitos escolares, perpassando os processos educacionais até os sujeitos envolvidos na alfabetização, ou seja, avaliando o sistema educacional, o currículo, a escola, o professor e as próprias práticas de avaliação.

Em grande parte dos cadernos, a avaliação diagnóstica é ressaltada como um princípio norteador das açóes pedagógicas. Os textos contidos nos cadernos sugerem que avaliaçóes diagnósticas sejam feitas constantemente, por meio de registros diários do progresso das crianças, enfatizando uma avaliação ao início, no meio e ao final de anos letivos ou sequências didáticas, reconhecendo o crescimento ou dificuldades dos alunos e fazendo planejamentos pedagógicos de acordo com a necessidade dos alunos (cf. BRASIL, Ano 1 Unidade1, 2012).

Nota-se pela descrição do referido eixo de análise que a avaliação formativa e seus fundamentos estáo presentes em parte dos cadernos, conforme apregoado por Scallon (1988), Allal (1986) e Hadji (2011). No entanto, destaca-se no material que o PNAIC tem como um de seus objetivos elevar os índices de avaliações externas e a avaliação em larga escala é apresentada como uma avaliação diagnóstica; tal afirmação contradiz em alguns aspectos os fundamentos da avaliação formativa, uma vez que as avaliaçóes em larga escala como a Provinha Brasil náo consideram as eventualidades na aplicação das provas, náo permitem verificar as condiçóes do aluno e do ambiente para a realização da avaliação e desconsideram o processo de construção dos 
saberes que são contemplados em uma avaliação diagnóstica na perspectiva de avaliação formativa.

- Avaliaçóes em larga escala:

Sendo uma das metas do PNAIC elevar os índices de aprendizagem nas avaliaçóes externas, encontramos em alguns cadernos pareceres sobre o programa e os resultados de avaliaçôes externas. No total, foram 107 incidências em 13 cadernos.

Em alguns cadernos encontram-se críticas à maneira como os resultados de avaliações externas têm sido usados nas escolas para culpabilizar professores e gestores pelo insucesso escolar. Os cadernos ressaltam que os resultados de tais avaliaçóes são relevantes como instrumento de melhoria de todo o processo educacional, a fim de se pensar as políticas educacionais, porém o que acontece de fato é que os resultados acabam levando a uma grande concentração de esforços para ensinar os alunos a responderem as questóes das avaliações externas e não há esforços em busca de efetivar saberes (cf. BRASIL, 2015, Caderno para gestores).

Mesmo com a implementação de rankings e a promoção/bonificação de instituiçôes com índices elevados nas avaliações em larga escala, os cadernos de formação alertam para o baixo índice de aprendizagens denunciadas pelas avaliaçóes externas; este fator alerta não só para a problematização quanto aos medidores externos como também para a reflexão sobre os resultados da implementação do PNAIC, que foi instituído para beneficiar as aprendizagens.

- Procedimentos e instrumentos de avaliação:

Este eixo mostra a ideia da relação entre avaliar e ensinar e a necessidade de tomada de consciência do que avaliar. Os instrumentos e procedimentos de avaliação precisam ser intencionalmente planejados pelo docente e cabe ao coordenador da escola promover a socialização deles entre os professores. Foram identificadas, neste eixo, 41 incidências em 15 cadernos. Os pressupostos apresentados estão de acordo com a ideia da relação da regulação do ensino e da aprendizagem para a promoção e sucesso escolar (LOURENÇO; PAIVA, 2016).

\section{Categoria 2. Formação docente}

- Sugestôes de atividades para professores:

Neste eixo destacam-se,de forma explícita, sugestôes de atividades a serem realizadas durante as formaçóes de professores do PNAIC (cf. BRASIL, Cad. 1, 2015). Há 56 incidências em 18 cadernos. As sugestôes de atividades discutem o modo pelo qual os professores têm avaliado os processos de ensino, 
os instrumentos utilizados, o diagnóstico de aprendizagens e dificuldades dos estudantes e a forma de aplicar e preencher quadros de acompanhamento de aprendizagem e perfil do grupo. Embora os pressupostos da avaliação formativa não apareçam diretamente nos trechos selecionados, nota-se que a indicação da leitura de cadernos já analisados ora está de acordo com a perspectiva cognitivista, oraaproxima-se mais de um controle da perspectiva neo(behaviorista), para a superação das dificuldades por meio de recuperação (ALLAL, 1986).

- Depoimento de professores:

O eixo apresenta 46 incidências em 17 cadernos e traz trechos de depoimentos dos professores que retratam a interlocução entre processos de avaliação e o desenvolvimento de atividades e de observaçóes em diferentes disciplinas; este eixo também aborda a ideia da avaliação formativa e da participação dos alunos em alguns momentos do processo avaliativo (cf. BRASIL, Cad. 3, 2014; BRASIL, Cad. 6, 2015). Os depoimentos trazem a perspectiva de acompanhamento, feedbacks, reorganização, próximo dos pressupostos da avaliação formativa e autorregulação.

- Açóes docentes:

Neste eixo categorizamos os conteúdos que relacionavam o processo de avaliação com o planejamento, a organizaçáo e a autorregulação, que retratam as ações do docente no processo de ensino e aprendizagem. Foram detectadas 44 incidências em 21 cadernos de conteúdos referentes a este eixo. De forma geral, em todas as incidências a perspectiva de avaliação formativa estava presente.

Nos cadernos avaliados foi possível compreender que a ação e a tomada de decisóes do docente devem se pautar nos três elementos cruciais do constructo da autorregulação: planejar, executar e avaliar, "afinal, é no âmbito da gestáo (escolar e de Rede) que são tomadas decisóes que incidem diretamente sobre a prática docente, no que se refere ao planejamento, à execução e à avaliação" (BRASIL, Caderno para Gestores, 2015, p.41).

O professor é visto nos documentos como um profissional que tem autonomia na ação educativa, tendo a liberdade de selecionar instrumentos de diagnóstico e de avaliação (cf. BRASIL, Cad. 5, 2015). Nota-se que o documento traz a ideia de que o planejamento deve estar articulado com o processo de avaliaçáo do aluno, da própria avaliação e das práticas de ensino (cf. BRASIL, Cad. 1, 2015).

Ainda neste eixo consideram-se as efetivas necessidades de aprendizagens das crianças e o papel do professor como mediador durante a realização das atividades, considerando a importância de feedbacks contínuos, principalmente quando o aluno ainda náo aprendeu os conteúdos necessários. Esses aspectos contemplam a perspectiva da avaliação formativa, proposta por Hadji (2011), ressalta-se que é um elemento fundamental para uma aprendizagem 
significativa, pois proporciona ao aluno compreender seus ganhos e melhorias a serem feitas.

- Formaçáo de professores e gestores:

O eixo traz elementos dos processos de avaliação e autoavaliação, relacionados à formação dos professores e gestores, que estão presentes nas propostas do PNAIC. Referentes a este eixo foram identificadas 37 incidências em 6 cadernos.

Os cadernos apresentam fortemente a perspectiva de autoavaliação ligada à formação continuada dos docentes e gestores, propondo que haja constantemente avaliaçóes dos formadores, professores, dos programas desenvolvidos pelas secretarias, das equipes de coordenação pedagógica, do próprio documento de orientaçóes curriculares e da formação continuada do PNAIC. A autoavaliaçáo dos processos mencionados contribui para a reflexão sobre as ações e o planejamento dos mesmos, partindo para uma avaliação formativa do processo de formação (cf. BRASIL, Caderno Apresentação, 2015).

No entanto, a autoavaliação do aluno é insipiente nos cadernos de formação. Como destacado, a autoavaliação permite o processo de metacognição, uma vez que o aluno reflete e repensa sobre as estratégias utilizadas e novas estratégias para alcançar os objetivos de aprendizagem. A ação didática necessitaconsiderar esse aspecto se tem como objetivo a garantir a otimizaçáo das aprendizagens dos alunos. Diante deste fato, temos a autorregulação como finalidade para o processo de aprendizagem e a autoavaliação como um instrumento fundamental, como um meio para alcançar tais regulaçóes.

\section{Categoria 3. Formação discente}

- Ações discentes:

Neste eixo são relatadas as incidências e trechos dos materiais que denotam o desenvolvimento de um processo de autoavaliação e autorregulação dos alunos, foram detectadas 18 incidências em 9 cadernos.

Percebe-se que, comparado com outros eixos, essese apresenta em menor número deincidência o que nos leva a inferir que a ação do aluno é pouco considerada quando se trata da avaliaçáo, divergindo da teoria que fundamenta este estudo e da própria fundamentação teórica dos cadernos de formação do PNAIC, que se pautam na avaliação formativa.

As ações de autorregulação e autoavaliação são ressaltadas nos cadernos, principalmente quando relacionadas aos procedimentos que os professores devem utilizar nas diferentes disciplinas, por exemplo, quando desenvolvem projetos didáticos, momento em que os alunos podem se tornar mais responsáveis e participativos nas atividades escolares. 
Em alguns dos cadernos apresentados nesse eixo é possível verificar a ação da criança quando há explicaçóes sobre o desenvolvimento de projetos didáticos, "por propiciarem momentos de planejamento conjunto, realização de atividades de modo compartilhado e avaliação, também favorecem o desenvolvimento da autonomia das crianças, que se tornam agentes ativos do próprio processo educativo, como ocorreu na experiência relatada” (BRASIL, Cad. 3, 2014, p.87).

Nota-se que o papel do aluno fica reduzido a apenas alguns momentos, o que se distancia das definiçôes do papel do aluno na avaliaçáo formativa e autorregulação destacados por Hadji (2011), Rosário (2004), Allal (1986) e Zimmerman e Schunk (2011), no qual o estudante é ativo e protagonista em seus estudos. Esse distanciamento conflita com a perspectiva adotada no material de formação, evidenciando certa fragilidade na ligação entre o papel dos estudantes e do professor no momento da avaliação e desconfigurando a proposta formativa.

\section{Considerações finais}

O texto apresentou aspectos sobre a avaliação da aprendizagem nos Cadernos de Formaçáo do PNAIC, tendo como elemento de análise os fundamentos da avaliação formativa na perspectiva cognitiva e da autorregulação. Os dados apontam diferentes concepçóes nos Cadernos do PNAIC. Ao mesmo tempo em que convida os docentes a realizarem o acompanhamento dos processos de aprendizagem dos alunos na perspectiva da avaliação formativa cognitiva, o texto é prescritivo, aponta para açôes de recuperação e dá ênfase às avaliaçóes externas.

Enfatiza-se que a implementação e execução de políticas públicas requerem o engajamento dos profissionais da educação, quer na esfera federal, quer na estadual e municipal. Os impactos das políticas educacionais, dos materiais de orientação, como os apresentados pelo PNAIC, podem ser positivos ou negativos. Nota-se nos próprios documentos do referido programa o reconhecimento de que há distorçôes na compreensão das políticas de avaliaçóes externas, quando apontam para o treinamento dos alunos para a realizaçáo de provas.

Para além das pesquisas que se propóem analisar diferentes facetas do material (PARISOTTO; OLIVEIRA, 2016; FERREIRA; FONSECA, 2017; AGUIAR; BRICHI; ZAPATA, 2017; ALFLEN; PIANOVSKI, 2018), há que se considerar principalmente a escola e seus integrantes (gestores, professores, pais e alunos) que são afetados diretamente pelas políticas. Esses agentes têm papel importante na análise das políticas e materiais e, a partir do diálogo interno, deve-se decidir e determinar quais os aspectos que podem contribuir para o Projeto Político Pedagógico da escola e não, o que comumente acontece, adequar o Projeto em favor das políticas. 
Por fim, chamamos a atenção para a necessidade de continuidade dos programas implementados nos governos federais e anunciamos duas questóes que podem dar continuidade à discussão apresentada nesse artigo: Com a implementação do Programa Mais Alfabetização, o que acontecerá com todo investimento realizado pelo PNAIC? Novas orientaçóes sobre a avaliação formativa serão apresentadas? Frente ao exposto, compreende-se que o processo de avaliação formativa é um caminho para alcançar aprendizagens significativas, os cadernos de formação do PNAIC indicam um trabalho nessa perspectiva, mas é necessário um posicionamento crítico e comprometido para que haja mudanças reais na concepção sobre a avaliação. O protagonismo estudantil, como demonstrado pela análise realizada ficou em segundo plano o que é contraditório com a avaliação formativa.

Se buscamos uma escola democrática, aprendizagens efetivas e avaliaçóes que favoreçamnovas aprendizagens e envolvimento dos estudantes, será fundamental,esforços para compreender as necessidadesdos estudantes, as formas ativas departicipaçãonos próprios processos educacionais, e promover o ensino de estratégias para aautorregulação da aprendizagem.

\section{Referências}

ABRECHT, R. A avaliaçáo formativa: uma análise crítica. Porto: Asa, 1986.

AGUIAR, M. Ap. L. de; BRICHI, C. C.; ZAPATA, S. I. Formação continuada para professores no pacto nacional pela alfabetização: continuidades, rupturas e ressignificações. Cad. CEDES, Campinas, n.102, p.201-218, 2017. Disponível em: http://www.scielo.br/scielo.php?script=sci_arttext\&pid=S01013262201700 0200201\&lng=en\&nrm=iso. Acesso em: 20 jul. 2018.

ALFLEN, A. F. M.; VIEIRA, A. M. D. P. A. Experiência cearense que inspirou o Pacto Nacional Pela Alfabetização na Idade Certa. Revista Teias, Rio de Janeiro, n.53, p.246-260, 2018. Disponível em: http://www.e-publicacoes.uerj.br/index. php/revistateias/article/view/30092/25366. Acesso em: 15 jul. 2018.

ALLAL, L. Estratégias de avaliação formativa: concepções psicopedagógicas e modalidades de aplicação. In ALLAL, L.; CARDINET, J.; PERRENOUD, P. A avaliaçáo formativa num estudo diferenciado.Coimbra: Almedina, p. 175199, 1986.

ALVES, M. P. Currículo e avaliaçáo: uma perspectiva integrada. Porto: Porto editora, 2004.

BARDIN, L. Análise de conteúdo. São Paulo: Ediçōes 70, 2011. 
BRASIL. Lei 13.005 de 25 de junho de 2014. Plano Nacional de Educaçáo. Brasília: MEC/SEF, 2014. Disponível em: http://pne.mec.gov.br/18-planossubnacionais-de-educacao/543-plano-nacional-de-educacao-lei-n-13-005-2014. Acesso em: 12 fev. 2019.

BRASIL. Ministério da Educação. Entendendo o Pacto. Brasília: MEC, SEB, 2012. Disponível em: http://pacto.mec.gov.br/o-pacto. Acesso em: 25 jul. 2016.

BRASIL. Pacto Nacional pela Alfabetização na Idade Certa. A arte no ciclo de alfabetizaçáo. Caderno 06. Brasília: MEC, SEB, 2015. 104 p. Disponível em: http://pacto.mec.gov.br/images/pdf/Cadernos_2015/cadernos_novembro/ pnaic_cad_6_19112015.pdf. Acesso em 01 ago. 2016.

BRASIL. Pacto Nacional pela Alfabetização na Idade Certa. A oralidade, a leitura e a escrita no ciclo de alfabetizaçáo/Caderno 05. Brasília: MEC, SEB, 2015. 112p. Disponível em: http://pacto.mec.gov.br/images/pdf/Cadernos_2015/ cadernos_novembro/pnaic_cad_5_19112015.pdf. Acesso em 01 ago. 2016.

BRASIL. Pacto Nacional pela Alfabetização na Idade Certa. Currículo na perspectiva da inclusáo e da diversidade: as Diretrizes Curriculares Nacionais da Educação Básica e o ciclo de alfabetizaçáo/Caderno 01. Brasília: MEC, SEB, 2015. 104p. Disponível em: http://pacto.mec.gov.br/materiais-listagem/item/ download/12_ab2c739d2e8293712078e7b6b0c12abb. Acesso em: 01 ago. 2016.

BRASIL. Pacto Nacional pela Alfabetização na Idade Certa. Currículo na alfabetizaçáo: concepçóes e princípios/Ano 1 Unidade 1. Brasília: MEC, SEB, 2012. 57p. Disponível em: http://pacto.mec.gov.br/images/pdf/Formacao / Ano_1_Unidade_1_MIOLO.pdf. Acesso em: 01 ago. 2016.

BRASIL. Pacto Nacional pela Alfabetização na Idade Certa. Gestão Escolar no Ciclo de Alfabetização/Caderno para gestores. Brasília: MEC, SEB, 2015. 76p. Disponível em: http://pacto.mec.gov.br/images/pdf/Cadernos_2015/cadernos_ novembro/pnaic_cad_gestores.pdf. Acesso em: 01 ago. 2016.

BRASIL. Pacto Nacional pela Alfabetização na Idade Certa. Interdisciplinaridade no ciclo de alfabetizaçáo/Caderno 03. Brasília: MEC, SEB, 2015. 116p. Disponível em: http://pacto.mec.gov.br/images/pdf/Cadernos_2015/cadernos_ novembro/pnaic_cad_3_19112015.pdf. Acesso em 01 ago. 2016.

BRASIL. Pacto Nacional pela Alfabetizaçáo na Idade Certa. Interdisciplinaridade no ciclo de alfabetizaçáo/Caderno de Apresentaçáo. Brasília: MEC, SEB, 2015.76p. Disponível em: http://pacto.mec.gov.br/images/pdf/Cadernos_2015/ cadernos_novembro/pnaic_cad_apresentacao.pdf. Acesso em 01 ago. 2016.

CARDINET, J. Évaluation scolaire et pratique. Bruxelles: Éditions De Boeck, 1988. 
DANTAS, C.; RODRIGUES, C. C. Estratégias metacognitivas como intervenção psicopedagógica para o desenvolvimento do automonitoramento. Rev. psicopedag., São Paulo, v.30, n.93, p.2026-2035, 2013. Disponível em:<http:// pepsic.bvsalud.org/scielo.php?script=sci_arttext\&pid=S0103848620130003000 09\&lng=pt\&nrm=iso. acessos em 21 jul. 2018.

ESTEBAN, M. T. (Org). Avaliaçáo: uma prática em busca de novos sentidos. Rio de Janeiro: DP\&A, p. 7-28, 1999.

FERNANDES, D. Avaliaçáo das aprendizagens: desafios às teorias, práticas e política. Lisboa: Texto Editora, 2005.

FERREIRA, P. de F.; FONSECA, M. S. A cultura da performatividade na organização do trabalho pedagógico: a formação matemática nos cadernos do Pacto Nacional pela Alfabetização na Idade Certa (Pnaic). Ensaio: aval.pol.públ. Educ., Rio de Janeiro, n.97, p.809-830, 2017. Disponível em: http://www. scielo.br/scielo.php? script=sci_arttext\&pid=S0104-40362017000400809\&lng $=$ pt\&nrm=iso. Acesso em: 20 jul. 2018.

HADJI, C. Ajudar os alunos a fazer a autorregulaçáo da sua aprendizagem: Por quêe Como? (Visando um ensino com orientaçáo construtivista). Pinhais: Editora Melo, 2011.

HADJI, C. Avaliaçáo desmistificada. Porto Alegre: Artmed, 2001.

LOURENÇO, A.A.; PAIVA, M.O.A. Autorregulação da aprendizagem: uma perspectiva holística. Ciências e Cogniçáo, v.21, n.1, p.33-51, 2016.

MARCONI, M. A.; LAKATOS, E. M. Técnicas de Pesquisa. São Paulo: Atlas, 2007.

PARISOTTO, A. L. V.; OLIVEIRA, A. R. de. Formação Docente: Uma reflexão sobre os princípios norteadores no pacto nacional pela alfabetização na idade certa. Revista Teias, Rio de Janeiro, Edição Especial - Práticas nas IES de formação de professores para a EJA, p.194-208, 2016. Disponível em: http:// www.e-publicacoes.uerj.br /index.php/revistateias/article/view/24813/18084. Acesso em: 15 jul. 2018.

PERRENOUD, P. Avaliaçáo. Da Excelência à Regulaçáo: entre duas lógicas. Porto Alegre: Artmed, 1999.

ROSÁRIO, P. Estudar o estudar: As (Des) venturas do Testas. Porto. Porto Editora, 2004.

SCALLON, G. L'évaluation formative des apprentissages. Québec et Otawa: Les presses de l'université Laval, 1988. 
ZANCHETTA JR, J. Práticas de leitura literária e a contribuição do PNAIC. Rev. Bras. Educ., Rio de Janeiro, n.68, p.147-167,2017. Disponível em: http://www. scielo.br /scielo.php?script=sci_arttext\&pid=S1413-24782017000100147\&lng =pt\&nrm=iso. Acesso em: 20 jul. 2018.

ZIMMERMAN, B.J. Investigating self-regulation and motivation: Historical, background, methodological developments, and future prospects. American Educational Research Journal, v.45, n.1, p.166-183, 2008.

ZIMMERMAN, B.J.; SCHUNK, D. Handbook of self-regulation of learning and performance. London: Routledge, 2011. 